\title{
MicroRNA-34a regulates epithelial-mesenchymal transition and cancer stem cell phenotype of head and neck squamous cell carcinoma in vitro
}

\author{
ZHIFENG SUN $^{1,2^{*}}$, WEIMING HU ${ }^{2,4^{*}}$, JINFENG XU ${ }^{3}$, ANDREAS M. KAUFMANN ${ }^{3}$ and ANDREAS E. ALBERS ${ }^{2}$ \\ ${ }^{1}$ Clinic for Gynecology, The Affiliated Hospital of Hubei University for Nationalities, Enshi, P.R. China; \\ ${ }^{2}$ Department of Otolaryngology, Head and Neck Surgery and ${ }^{3}$ Clinic for Gynecology, \\ Charité-Universitätsmedizin Berlin, Berlin, Germany; ${ }^{4}$ Department of Otorhinolaryngology, \\ Head and Neck Surgery, Zhejiang Provincial People's Hospital, Hangzhou, P.R. China
}

Received May 18, 2015; Accepted June 26, 2015

DOI: $10.3892 /$ ijo.2015.3142

\begin{abstract}
MicroRNAs (miRs) are short non-coding single stranded RNAs regulating the translation of target mRNAs in normal and cancer cells in which they are frequently dysregulated promoting tumor progression. Cancer stem cells (CSCs) of head and neck squamous cell carcinoma (HNSCC), identified by aldehyde-dehydrogenase expression (ALDH), are a cell subset within the tumor cell population that takes part in the genesis and progression of cancer. The relevance of epithelial-mesenchymal transition (EMT) has recently been recognized for tumor development and metastasis. Several studies have illustrated that miRs regulate EMT of CSC. CSC from 8 HNSCC lines, 4 of which are human papillomavirus (HPV)-positive, were enriched by spheroid culture (spheroid-derived cells, SDC) and compared to their parental monolayer-derived cells (MDC) to analyze expression patterns of miR-34a, CSC-related transcription factors (CSC-TFs: Sox2, Nanog, Oct3/4) and EMT-related TFs (EMT-TFs: Twist, Snail1, Snail2) by RT-qPCR. Flow cytometry was used to quantify and enrich $\mathrm{ALDH}^{+} \mathrm{CSC}$. Transfection of miR-34a mimics was used to evaluate its regulatory potential for CSC marker profiles as well as CSC- and EMT-TFs expression in HNSCC-SDC. Invasive, colony-forming and clonogenic capability of the miR-34a mimics transfected SDC after sorting for $\mathrm{ALDH}^{+}$and $\mathrm{ALDH}^{-}$cells was assessed by Matrigel invasion, clonogenicity and spheroid formation assay, respectively.
\end{abstract}

Correspondence to: Dr Andreas E. Albers, Department of Otolaryngology, Head and Neck Surgery, Charité-Universitätsmedizin Berlin, D-12200 Berlin, Germany

E-mail: andreas.albers@charite.de

*Contributed equally

Key words: transfection, mimics, HPV, metastasis, microRNA, p53, miR34a, epithelial-mesenchymal-transition, cancer stem cells, head and neck cancer, aldehyde-dehydrogenase
miR-34a expression levels were significantly downregulated in the majority of SDC derived from HNSCC-lines as compared to parental MDC (-1.6-16.4-fold). For EMT- and CSC-related TF expression, all HNSCC-derived SDC showed a significantly increased level compared to parental MDC ( $\leq 36.8$-fold). Significantly increased expression of ALDH was found in SDC (2-3-fold). Compared to the $\mathrm{HPV}^{+}$, the $\mathrm{HPV}^{-}$ group showed a significantly higher mean expression level of EMT-TFs, CSCs-TFs and ALDH(30.3 v.s. 12.8\%). Transfection of miR-34a mimics significantly reduced the EMT- and CSC-related TF expression level in UM-SCC9 (HPV ${ }^{-}$) and UM-SCC47 (HPV $\left.{ }^{+}\right)$SDC. Simultaneously, the ALDH expression was reduced significantly (1.5-2-fold) and the invasive capacity $(\leq 30 \%)$ and clonogenicity of HNSCC-SDC was also inhibited by transfection of miR-34a mimics compared to controls. Restoration of miR-34a significantly inhibited the capability for EMT formation of CSC-phenotype and functionally reduced clonogenic and invasive capacity in HNSCC cell lines. Therapeutic modulation of miR-34a in HNSCC and CSCs may reduce the rate of metastasis and recurrence of tumors after therapy.

\section{Introduction}

Head and neck squamous cell carcinoma (HNSCC) with $>600,000$ newly diagnosed cases per year is the sixth most common cancer in the world (1). In developed countries the average 5-year survival rate is $\sim 50 \%$ (2). Improvements during the past decades in radio- and chemotherapy, and recently introduced targeted antibody therapy and improved surgical procedures have resulted in a significantly enhanced quality of life for cancer patients. However, local and distant recurrence is common in HNSCC and during the past years rates of survival have only marginally improved (3).

According to the cancer stem cell (CSC) theory, tumor formation, relapse after therapy and the development of metastases is thought to involve CSC in different phenotypic and functional states. This particular subset of cells was named cancer stem (like) cells (CSCs), similar to that conceptualised in normal tissue as stem cells (4). To date, the existence of 
CSCs have been identified in several human hematologic and solid tumors, including leukemia, bladder cancer, breast cancer, colon carcinoma, HNSCC and pancreatic cancer (5-9). The CSC theory suggests that only a subpopulation of cells in a tumor has the ability to self-renew, differentiate and regenerate similar tumors, as demonstrated in vitro (10-13) and by xenotransplantation into immuno-deficient mice (14). These cells display also some resistance to conventional therapy $(11,12)$.

Spheroid culture is an effective and convenient way to enrich the CSC population present in the cancer cell population and is thus increasingly being used, sometimes in combination with further enrichment by specific markers, to evaluate functional stem cell activity in normal tissue and putative CSC. The ability of CSC to form spheroids was first observed in cells derived from the central nervous system in 1992 (15). Todaro et al found that cells isolated from the striatum of adult mouse brain could be clonally expanded by culturing spheres, and the cells generated both astrocytes and neurons (16). The ability of isolated cells to form anchorage-independent spheres in culture was demonstrated in breast, colon, HNSCC and melanoma $(6,7,17)$. In HNSCC cell lines, CSC cultured with this method showed a high level of CSC-marker expression such as CD44, CD133 and ALDH $(10,18,19)$.

Epithelial to mesenchymal transition (EMT) is a key event in metastasis and increasing evidence suggests there is a link between EMT and CSCs (20-23) that has also been demonstrated for HNSCC (10). Mani et al (22) and Hindriksen and Bijlsma (24) reported that induction of an EMT in human mammary epithelial cells led to an increased expression of CSC markers and in pancreatic cancer the occurrence of EMT is often accompanied by the activation of CSC-related pathways. EMT is a physiological process that plays an important role during embryonic development and morphogenesis (25). Important characteristics of EMT are a loss of polarity of the epithelial cells, loss of intercellular contacts, acquisition of mesenchymal features and phenotype along with an increased cellular motility (23). Therefore, during EMT the expression of epithelial markers, such as E-cadherin decreases while the expression of mesenchymal markers, such as $\mathrm{N}$-cadherin, vimentin and $\alpha$-smooth muscle actin increases $(10,25,26)$. In recent years it has been demonstrated that EMT is involved in the development of metastasis by increased cellular motility and invasiveness $(23,25,27)$ resulting in a more metastatic phenotype $(28,29)$. During the EMT process, several changes in gene expression, such as increased Snail1, Snail2 and Twist transcription factors can be observed $(23,30)$. We and others have demonstrated a link between EMT and CSCs. For example the expression of the EMT-marker Snail1/2 or Twist is increased in CSC, that are involved in the loss of the epithelial phenotype and the acquisition of the mesenchymal phenotype (10,31-33). In the past few years, it became evident that the induction of EMT not only promotes tumor cell metastasis and invasion, but it is also involved in drug resistance and enrichment of CSCs (21-23,34).

MiRs are a family of 21-25 nucleotide long, non-coding endogenous RNAs, that act by binding to the target mRNA 3'-untranslated region inducing mRNA degradation or repression of mRNA translation (35). A single miR may regulate several mRNAs and one mRNA can be targeted by dozens of miRs. Although small, miRs play an essential role in biological processes, such as development, metastasis, proliferation and apoptosis (35). Early investigations demonstrated that miRs control embryonic stem cell (ESC) properties including self-renewal and differentiation. Later studies have shown that abnormal expression/functions of miRs are involved in tumorigenesis (36).

MiR34a is a tumor suppressor which directly targets p53 on a post-transcriptional level. In p53-deficient human pancreatic cancer cells, overexpression of miR-34a inhibited cell proliferation, cell cycle progression, self-renewal, EMT and invasion, indicating that miR-34a may restore p53 function, potentially directly via the downstream targets Notch and Bcl-2 which are involved in CSC differentiation and self-renewal (37). In prostate cancer, miR-34a was reported to directly repress CSC properties and metastasis. In breast cancer, ectopic miR-34a expression reduced CSC properties and enhanced sensitivity to chemical treatment. Thus, miR-34a is considered a tumor suppressor which represses 'stemness' features and function. In HNSCC cell lines, miR34a was found downregulated in HNSCC and -lines (38). However, miR-34a expression and function of in HNSCC is not clear yet.

\section{Materials and methods}

Cell lines. Eight HNSCC cell lines were used: UD-SCC1, -2 (gift of Henning Bier, University of Munich, Germany); UM-SCC9, -11B, -47, -104 (University of Michigan, Tom Carey, MI, USA) and UT-SCC33 (University of Turku, Reidar A. Grenman, Finland), 93VU147T (VU Medical Center, John P. de Winter, Amsterdam, The Netherlands). The HPV types were as follows: $\mathrm{HPV}^{+}$: UD-SCC2, UM-SCC47, UM-SCC104, 93VU147T; all HPV type 16+. HPV: UD-SCC1, UM-SCC9, UM-SCC11B, UT-SCC33. All cell lines were regularly tested for mycoplasma and found free of any contamination.

Spheroid culture. Adherent monolayer cells were grown in $75 \mathrm{~cm}^{2}$ cell culture flasks (BD Science, Franklin Lakes, NJ, USA) in DMEM (Invitrogen, Heidelberg, Germany) supplemented with $10 \%$ heat inactivated fetal bovine serum (FBS; Biochrom, Berlin, Germany) and $1 \%$ penicillin/streptomycin $(10,000 \mathrm{U} / \mathrm{ml}$ and $10,000 \mu \mathrm{g} / \mathrm{ml}$, respectively; Biochrom) at $37^{\circ} \mathrm{C}$ in humidified atmosphere with $5 \% \mathrm{CO}_{2}$, until $70-80 \%$ confluence. Cells were washed with PBS twice and detached using trypsin/EDTA solution (T/E; Biochrom). The reaction was stopped by adding complete culture medium. After centrifugation at $200 \mathrm{x}$ g for $5 \mathrm{~min}$, cells were resuspended in serum-free Quantum 263 (PAA), supplemented with $10 \mathrm{ng} / \mathrm{ml}$ $\mathrm{EGF}$ and $10 \mathrm{ng} / \mathrm{ml} \beta \mathrm{FGF}$ (Biochrom). To generate spheroids, single cells were plated in cell culture dishes (BD Falcon ${ }^{\mathrm{TM}}$, $100 \times 20 \mathrm{~mm}$ ) with a coated surface with $1 \%$ agarose at a specific density of $2 \times 10^{4}$ cells $/ \mathrm{ml}$. Cells were maintained at $37^{\circ} \mathrm{C}$ in humidified atmosphere with $5 \% \mathrm{CO}_{2}$ content.

Every three to four days, half of the medium was replaced. After 5-7 days, spheroid formation was checked and representative images were taken. For passaging or following experiments, culture medium with spheroids was removed from the dish and filtered through a $40-\mu \mathrm{m}$ mesh (BD Biosciences, Heidelberg, Germany) to collect the spheroids. For experiments, typically 2 nd or higher generation were used. 
Table I. Primer sequences used for RT-PCR (5'-3').

Transcript name

Nanog

Oct3/4

Sox 2

Snail1

Snail2

Twist

GAPDH (reference)

Hsa-miR-34a
Forward primer sequence

Reverse primer sequence
AAT ACC TCA GCC TCC AGC AGA TG

GAC AGG GGG AGG GGA GGA GCT AGG

GGG AAA TGG GAG GGG TGC AAA AGA GG

GGC GCA CCT GCT CGG GGA GTG

GGG GAG AAG CCT TTT TCT TG

GGA GTC CGC AGT CTT ACG AG

AGC TCC CAA AAA TAG ACG CAC

TGG CAG TGT CTT AGC TGG TTG T

\author{
TGC GTC ACA CCA TTG CTA TTC TTC \\ CTT CCC TCC AAC CAG TTG CCC CAA AC \\ TTG CGT GAG TGT GGA TGG GAT TGG TG \\ GCC GAT TCG CGC AGC A \\ TCC TCA TGT TTG TGC AGG AG \\ TCT GGA GGA CCT GGT AGA GG \\ TTC ATA GCA GTA GGC ACA AAG G
}

Aldefluor assay and FACS sorting. The ALDH activity of SDC and MDC was determined by using the Aldefluor assay kit (Stem Cell Technologies, Durham, NC, USA). For collection of the spheroids a $40 \mu \mathrm{m}$ mesh was used. Subsequently cells were dissociated into single cells by trypsin/EDTA digestion for $10 \mathrm{~min}$ at $37^{\circ} \mathrm{C}$ followed by 30 times up and down pipetting using a $1,000 \mu 1$ pipette tip. Then, the single-cell suspension was washed twice in PBS without $\mathrm{Ca}^{2+} / \mathrm{Mg}^{2+}$ and suspended in $1 \mathrm{ml}$ Aldefluor assay buffer containing $5 \mu \mathrm{l}$ ALDH substrate ( $1 \mathrm{ml} /$ per $1 \times 10^{6}$ cells) and incubated for $30-40 \mathrm{~min}$ at $37^{\circ} \mathrm{C}$ in the dark. As a negative control, for each sample, an aliquot was treated with $5 \mu$ l diethylaminobenzaldehyde (DEAB; $50 \mathrm{mmol} / \mathrm{l}$ ), a specific ALDH inhibitor. Following incubation, all samples were centrifuged for $5 \mathrm{~min}$ at $250 \mathrm{xg}$ and the supernatant was removed. After washing twice with buffer, cells were maintained in ALDH buffer on ice during all subsequent procedures.

For FACS sorting, cells were resuspended in PBS buffer at $1 \times 10^{7}$ cells per $\mathrm{ml}$ and run on an Aria cell sorter (BD Biosciences). The sorting gates were established, by negative control cells which were treated with the ALDH inhibitor DEAB.

Quantitative real-time PCR. To quantify the expression of mRNA, total RNA was isolated by TRIzol reagent (Life Technologies, Darmstadt, Germany) according to the manufacturer's instructions and then cDNA was prepared using the Omniscript First-Strand synthesis system (Qiagen, Hilden, Germany) random primers (Qiagen). RT-qPCRs were carried out using ABI Power SYBR Green mix (ABI, Applied Biosystems Inc, Foster City, CA, USA) and run on a Bio-Rad Chromo 4 (Bio-Rad, München, Germany). GAPDH was the reference gene.

For the detection of miR-34a, TRIzol reagent was used to extract total RNA according to the manufacturer's instructions. Poly A tailing and cDNA synthesis were performed by using the Ncode VILO miR cDNA (Invitrogen, Carlsbad, CA, USA) synthesis kit. The RT-qPCR analysis was performed on a Bio-Rad Chromo 4 (Bio-Rad) with Express SYBR GreenER ${ }^{\mathrm{TM}}$ qPCR SuperMix Universal (Invitrogen). GAPDH was the reference gene. Reactions were carried out in triplicate with controls; primer sequences are listed in Table I. The data were statistically analyzed by the modified $2^{-\Delta \Delta C t}$ value method (39).
Transfection of miRs. For transfection of miR mimics, spheroids were harvested using a $40 \mu \mathrm{m}$ mesh and dispersed into single cells as described above. The single cell suspension was plated at a density of $8 \times 10^{4}$ per well in 6-well ultra-low attachment plates with complete medium. Then cells were transfected with $50 \mathrm{nmol} / 1 \mathrm{miR}-34 \mathrm{a}$ mimic, negative control (NC) or MOCK control using the Lipofectamine RNAiMAX reagent (Invitrogen) in antibiotic-free Opti-MEM (Invitrogen) according to the manufacturer's instructions. After $6 \mathrm{~h}$, the medium was replaced with spheroid culture medium. Twenty-four hours after transfection, cells were harvested and processed for further analysis. The transfection efficiency was determined by cell counting after visualization of transfected cells with a BLOCK-iT ${ }^{\mathrm{TM}}$ Alexa Fluor Red Fluorescent Oligo using fluorescence microscopy.

The expression of the CSCs marker ALDH was assessed by FACS as described above at intervals of 24,48 and $72 \mathrm{~h}$ after transfection. Quantification of EMT- and CSC-related TF expression by transfected SDC were carried out by RT-qPCR.

Invasion assay. Warm $\left(37^{\circ} \mathrm{C}\right)$ culture medium was added to the interior of the inserts and bottom of BD BioCoat Matrigel Invasion Chambers (BD) and allowed to rehydrate for $2 \mathrm{~h}$ in a humidified tissue culture incubator, at $37^{\circ} \mathrm{C}$ in $5 \% \mathrm{CO}_{2}$ atmosphere. After rehydration, the medium was carefully removed without disturbing the layer of Matrigel ${ }^{\mathrm{TM}}$ matrix on the membrane. Next, cell suspensions (SDC transfected with miR-34a mimics and controls) were prepared in culture medium containing $5 \times 10^{4}$ cells $/ \mathrm{ml}$ for 24 -well chambers. DMEM $(750 \mu \mathrm{l})$ containing 10\% FBS serving as chemoattractant was added to the wells of the plate. Sterile forceps were used to transfer the chambers to the wells. Immediately $0.5 \mathrm{ml}$ of cell suspension $\left(2.5 \times 10^{4}\right.$ cells $)$ was added to the 24 -well chambers that were then incubated for $24 \mathrm{~h}$ in a humidified tissue culture incubator, at $37^{\circ} \mathrm{C}$ in $5 \% \mathrm{CO}_{2}$ atmosphere.

After incubation, the non-invading cells were removed from the upper surface of the membrane by gentle scrubbing and the cells on the lower surface of the membrane were stained with Giemsa. Cell counting was facilitated by photographing the membrane through the microscope and 3 fields per membrane of triplicate membranes were counted under x200 magnification (Axiovert, Axiovision, Zeiss, Germany). 


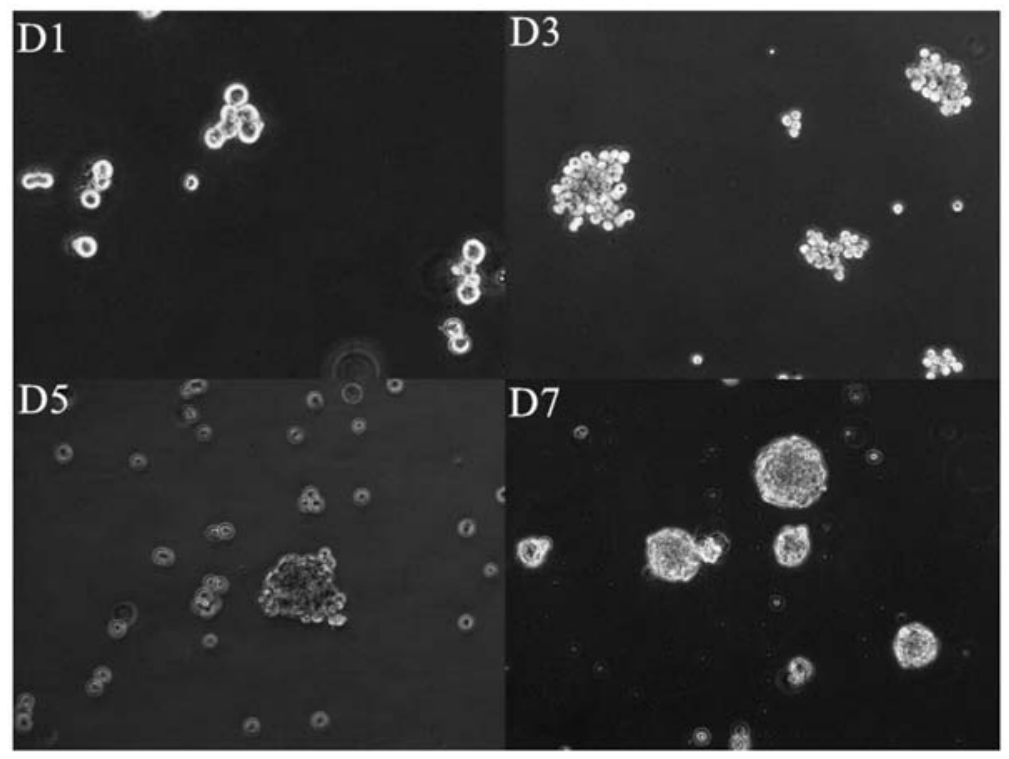

Figure 1. Time course of the spheroid culture (cell line UM-SCC9). Magnification, 100-fold. To determine the self-renewing ability, a single cell suspension generated from spheroids was plated at a clonal density of 1,000 cells per ml. After 7-10 days of subculture, tumor subspheroids (second generation) appeared, which contained 20-40 cells. When the spheroids were transferred back to a regular tissue culture flasks coated for monolayer cell culture, the spheroids adhered to the flask and cells migrated out from the spheroid and formed a confluent monolayer. The phenotype of these cells was identical to the parental cell lines as demonstrated before (10). Spheroids maintained in long-term culture up to the 10th generation, still showed this capacity for self-renewing ability that generated the parental HNSCC cells.

Colony formation assay and spheroid formation assay. A colony formation assay was used to assess the clonogenicity of miR-34a mimic-transfected UM-SCC9 cells sorted according to $\mathrm{ALDH}^{+}$and $\mathrm{ALDH}^{-}$. After FACS sorting, the $\mathrm{ALDH}^{+}$and $\mathrm{ALDH}^{-}$cells were placed in 6-well plates for transfection with miR-34a mimics.

After FACS sorting, $800 \mathrm{ALDH}^{+}$- and $\mathrm{ALDH}^{-}$cells, respectively, were inoculated into Ultra-low attachment 24-well plates (Corning, NY, USA) for transfection with miR-34a mimics, respectively. Cells were resuspended in serum-free Quantum 263 medium (Biochrom AG), supplemented with $10 \mathrm{ng} / \mathrm{ml}$ EGF and $10 \mathrm{ng} / \mathrm{ml} \mathrm{bFGF}$ (Biochrom). Fresh medium containing growth factors was added each week for 2 weeks.

Two weeks later, colonies were visualized by staining with Giemsa and viable colonies that contained $>50$ cells or were $>0.1 \mathrm{~mm}$ in size were counted with an ocular micrometer. The clone formation rate was calculated according to the formula: Clone formation rate $=$ number of formed colony $/$ number of seeded cells x $100 \%$.

Statistical analysis. For statistical evaluation of flow cytometric results, SPSS software (version 22; SPSS, Chicago, IL, USA) was used. Student's t-test was used to analyze statistical significance of the data.

For all RT-qPCR data, the expression analysis was performed using the modified $\Delta \Delta \mathrm{Ct}$ value method. Expression analysis and statistical evaluations was carried out by using the pair-wise fixed re-allocation randomization by Qiagen REST 2009 software (version 2.0.13).

\section{Results}

HNSCC cell lines contain cells with self-renewing capacity and the ability to form spheroids. Cells from 8 HNSCC cell lines were cultured in suspension for 7-10 days at a specific density of $2 \times 10^{4}$ cells $/ \mathrm{ml}$. The spheroid formation typically started at the first day after plating suspension cultures and the spheroid size became progressively larger. After 4-7 days the morphology of the spheroids did not change in size anymore, but the number of the spheroids in culture still continued to increase and the cell clusters became more compact (Fig. 1).

Independent of HPV-association, all HNSCC cell lines except UD-SCC2, formed highly compact spheroids. Only UD-SCC2 formed loose aggregates of cells easily dispersed by pipetting.

The CSCs marker ALDH shows a higher expression level in $S D C$ than in MDC. The Aldefluor assay has been successfully applied to detect ALDH-expression in CSCs from primary tumors or established cancer cell lines in various solid tumors, including HNSCC (40). We measured ALDH enzymatic activity of SDC of the eight HNSCC cell lines and their matched MDC to identify and quantify the stem cell-like population (Fig. 2A).

All HNSCC-derived SDC showed a significant increase in the number of $\mathrm{ALDH}^{+}$cells compared to parental MDC $(\mathrm{P}<0.05)$ (Fig. 2B). In the $\mathrm{HPV}^{+}$group, the cell line with the highest ALDH content was UM-SCC47 SDC (25.62 $\pm 0.50 \%)$ compared to the parental MDC $(11.05 \pm 0.16 \%)$. In the HPV group, the highest proportion of $\mathrm{ALDH}^{+}$cells was found in SDC derived from UM-SCC11b $(45.05 \pm 0.22 \%)$ which was 3.3-fold higher than in the corresponding parental MDC $(13.38 \pm 0.11 \%)$. Interestingly, ALDH expression was higher in SDC and MDC cultured from $\mathrm{HPV}^{-}$than from $\mathrm{HPV}^{+}$cell lines. The average percentage of $\mathrm{ALDH}^{+}$in in the MDC cell population derived from the four $\mathrm{HPV}^{-}$cell lines was $10.64 \pm 1.37 \%$ while in the four $\mathrm{HPV}^{+} \mathrm{HNSCC}$ cell lines on average $5.74 \pm 0.92 \%$ of cells were $\mathrm{ALDH}^{+}(\mathrm{P}<0.01)$. In SDC 


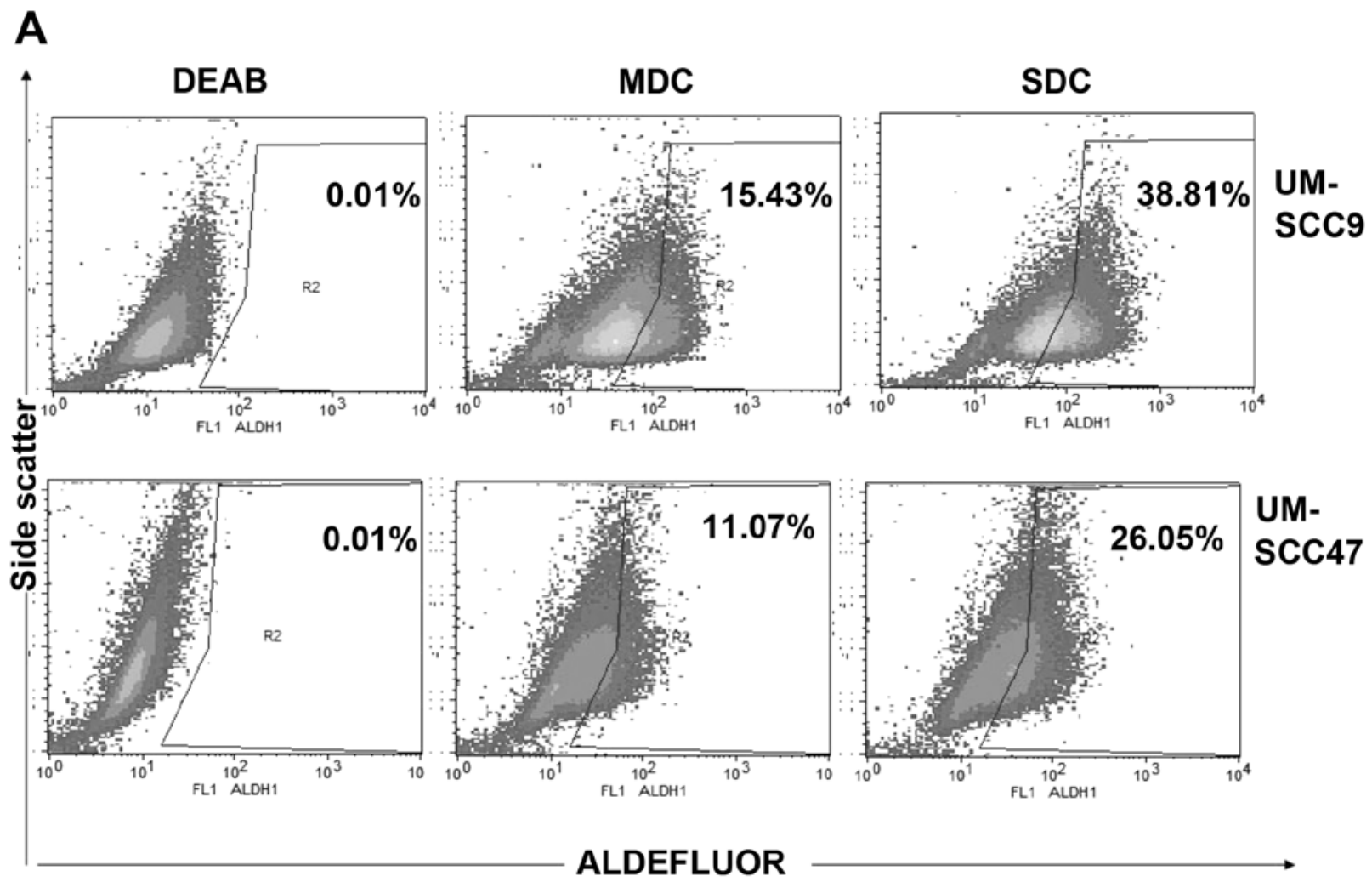

B

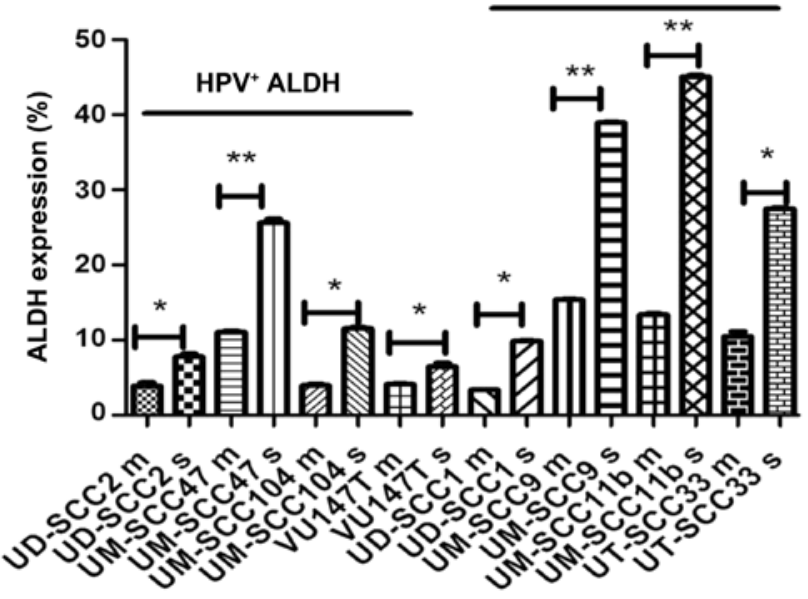

Figure 2. Expression of ALDH in HNSCC cell lines. (A) Representative example of a flow cytometric analysis of the expression of ALDH in SDC compared to MDC, and control SDC and MDC treated with DEAB, a specific inhibitor of ALDH. Region R2 depicts fluorescence intensity of $\mathrm{ALDH}^{+}$ cells. The number in the region represents the respective percentage of CSC in relation to all cells. (B) Mean percentage of $\mathrm{ALDH}^{+}$cells contained in the population of SDC and MDC of the investigated cell lines relative to their HPV status. The bars represent mean percentage \pm SD of three independent determinations $\left({ }^{*} \mathrm{P}<0.05,{ }^{* *} \mathrm{P}<0.01\right)$. $\mathrm{m}, \mathrm{MDC}$; s, SDC.

the average percentage of $\mathrm{ALDH}^{+}$in the $\mathrm{HPV}^{-}$cell lines was $30.33 \pm 4.03$ vs. $12.83 \pm 2.29 \%$ in the $\mathrm{HPV}^{+}$cell lines $(\mathrm{P}<0.01)$. These data correspond to our findings in HNSCC in vivo (41) and may also reflect the poor success rate with $\mathrm{HPV}^{+} \mathrm{HNSCC}$ tumor specimen in a xenograft mouse model due to a relatively low CSC content (42). Despite the fact that UD-SCC2 did not form compact spheroids, the SDC still showed an increased expression frequency of $\mathrm{ALDH}^{+}$as compared to its MDC.
Stemness-related TFs and EMT-related TFs are overexpressed in SDC. Sox 2, Oct3/4 and Nanog were reported as important TFs in maintaining stemness characteristics such as self-renewal and pluripotency in human embryonic stem cells and cancer cells (43). In line with previous findings (10), we confirmed as prerequisite for further work, that the mRNA level of Sox 2, Oct3/4 and Nanog were significantly increased in SDC of the eight investigated HNSCC cell lines (Fig. 3). The highest increase was observed in UM-SCC9 SDC, where a 36.81 \pm 5.66 -fold increase in Oct3/4 expression was found over the expression present in the parental MDC. The smallest difference was observed in UD-SCC2, where the Nanog expression showed a $0.28 \pm 0.12$-fold decrease. With regard to HPV-association, the mean Sox 2 expression ratio in $\mathrm{HPV}^{-} \mathrm{SDC} / \mathrm{MDC}$ was $8.21 \pm 0.79$ - vs. 1.83 \pm 0.36 -fold in $\mathrm{HPV}^{+}$ cell lines $(\mathrm{P}<0.01)$. The mean Oct $3 / 4$ expression ratio in $\mathrm{HPV}^{-}$ $\mathrm{SDC} / \mathrm{MDC}$ was $13.32 \pm 4.38$ - vs. 4.07 \pm 1.34 -fold in $\mathrm{HPV}^{+}$cell lines $(\mathrm{P}=0.07)$. Finally, the mean Nanog expression ratio was in $\mathrm{HPV}^{-} \mathrm{SDC} / \mathrm{MDC} 11.93 \pm 2.80$ - vs. 1.80 \pm 0.52 -fold in $\mathrm{HPV}^{+}$ cell lines $(\mathrm{P}<0.01)$.

Snail1, one of the key TFs involved in EMT, was significantly increased in all SDC generated from the 8 tested HNSCC cell lines as compared to MDC independent of their HPV status (1.04-27.28-fold, $\mathrm{P}<0.01)$. Interestingly, we also found that the mean expression ratio of Snail1 (HPV- SDC/MDC 20.72 vs. $\mathrm{HPV}^{+} 2.90$-fold, $\left.\mathrm{P}<0.05\right)$ and of Twist $\left(\mathrm{HPV}^{-} 9.87 \mathrm{SDC} / \mathrm{MDC}\right.$ vs. $\mathrm{HPV}^{+} 2.72$-fold, $\left.\mathrm{P}<0.05\right)$ was significantly higher in $\mathrm{HPV}^{-}$ $\mathrm{SDC} / \mathrm{MDC}$ than $\mathrm{HPV}^{+}$cell lines.

miR-34a is downregulated in HNSCC-derived SDC. We selected miR-34a due to its role as a tumor suppressor. We found that the expression of miR-34a was consistently and significantly 

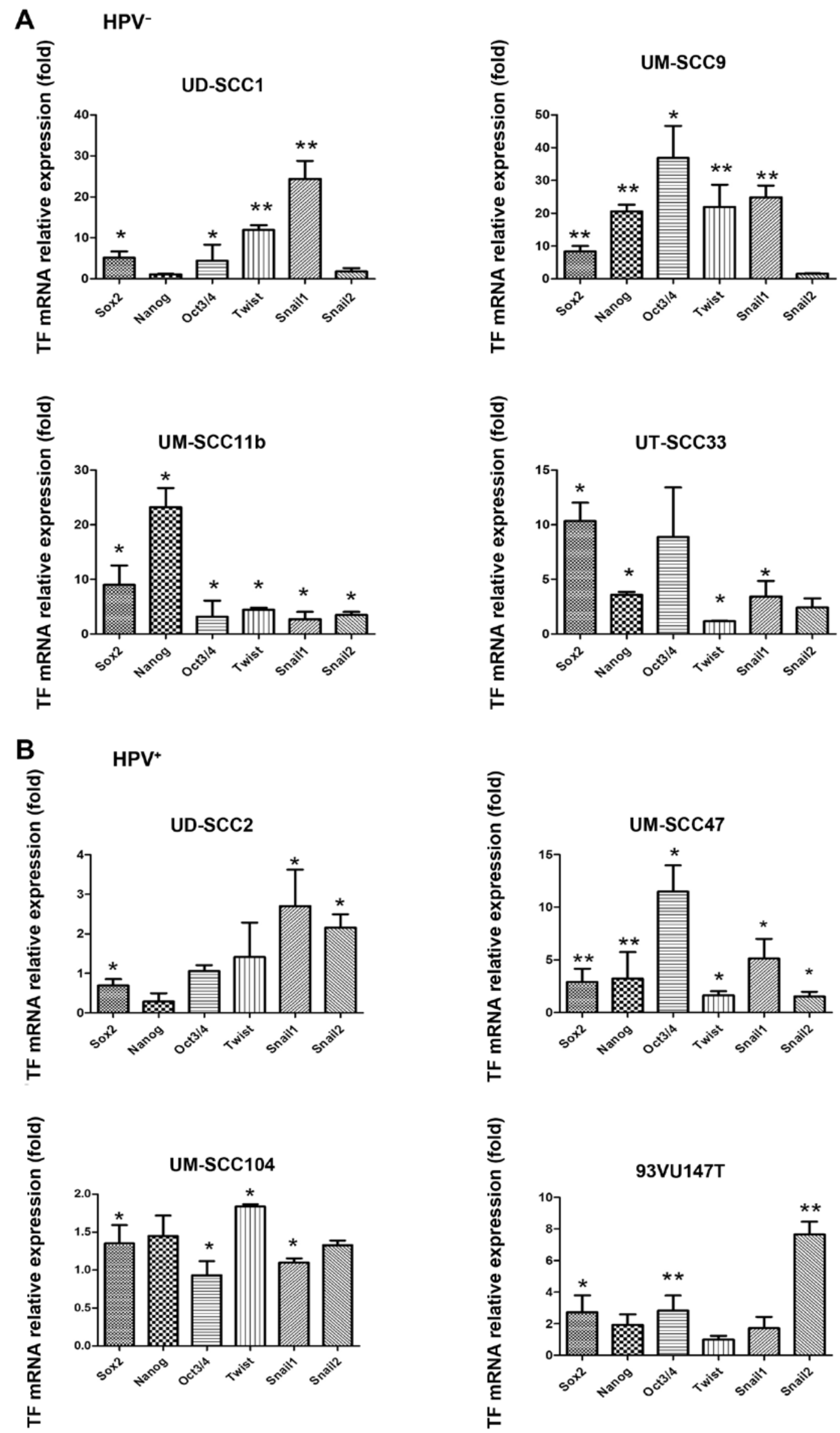

Figure 3. RT-qPCR analysis of mRNA expression of stemness-related TF and EMT-related TF. mRNA isolated from SDC and MDC was quantified for expression of the indicated panel of TF. The ratio of expression between SDC and MDC is represented by columns in the diagram (fold increase in SDC vs. $\mathrm{MDC})$. Mean value $\pm \mathrm{SD}$ of three independent determinations $\left({ }^{*} \mathrm{P}<0.05,{ }^{* *} \mathrm{P}<0.01\right)$. 


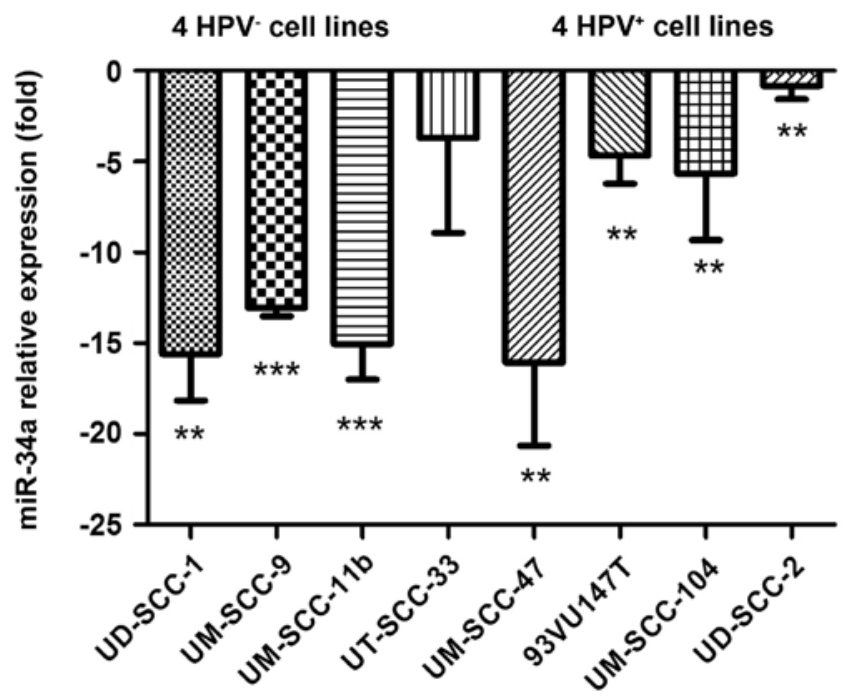

Figure 4. RT-qPCR analysis of miR-34a expression in HNSCC cell lines. The relative-fold changes in the HNSCC cell lines SDC to corresponding MDC is given. Mean value $\pm \mathrm{SD}$ of three independent determinations $\left({ }^{*} \mathrm{P}<0.05\right.$, $\left.{ }^{* *} \mathrm{P}<0.01,{ }^{* * * *} \mathrm{P}<0.001\right)$. downregulated in SDC compared to the parental MDC in all tested HNSCC cell lines (1.61-16.37-fold, $\mathrm{P}<0.05)$ (Fig. 4).

Overexpression of miR-34a reduces stemness- and EMT properties in HNSCC-SDC. To investigate the possibility that miR-34a serves as a link between EMT and CSCs by regulating EMT in HNSCC-SDC the following experiments were performed. First, in order to test whether miR-34a expression was sufficient to downregulate EMT and CSCs marker expression, ectopic miR-34a mimics were transiently transfected into UM-SCC 9 and UM-SCC47 cells.

The transfection efficiency of UM-SCC 9 was $94.33 \pm 0.57 \%$ and of UM-SCC47 $93.66 \pm 1.52 \%$. We also measured the transfection efficiency by verifying relative expression level of miR-34a mRNA after the transfection with miR-34a mimics and found that miR-34a mRNA level significantly increased after 24,48 and $72 \mathrm{~h}$, while the mock transfected group showed no differences in expression levels in comparison to the normal control (NC group) (Fig. 5A and B). The peak of miR-34a level was found $48 \mathrm{~h}$ post-transfection (UM-SCC9 4.49-fold, UM-SCC47 9.1-fold, P<0.01).
A UM-ScC9 spheroid transfection (HPV)

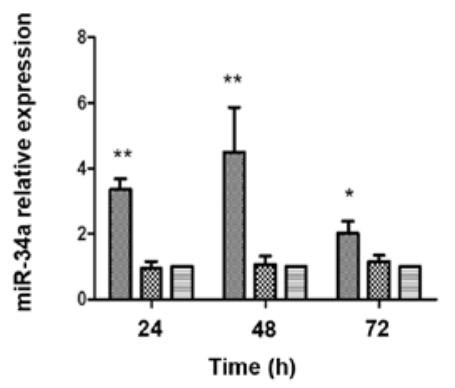

C UM-Scc9 spheroid transfection (HPV)

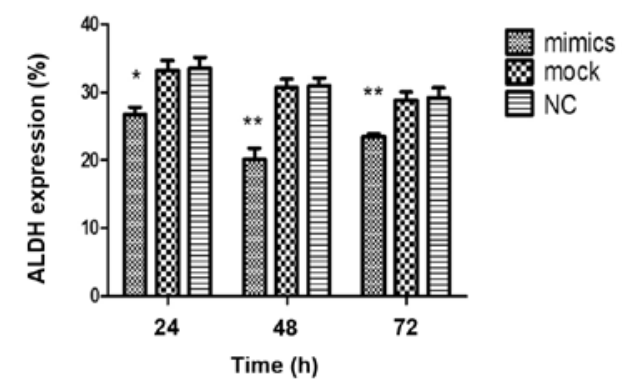

E UM-SCC9 spheroid transfection (HPV)

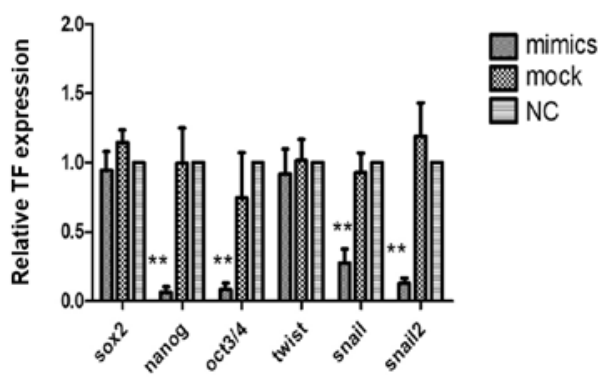

B

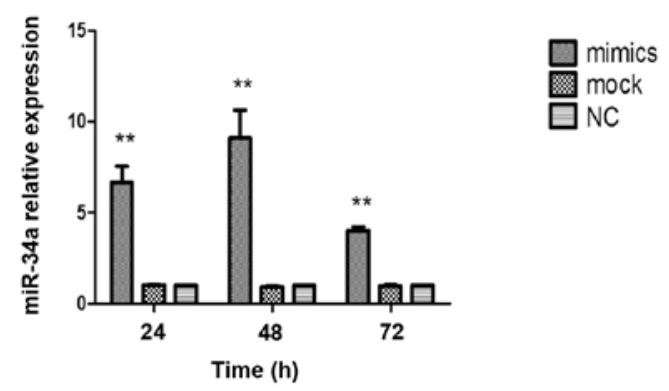

D UM-SCC47 spheroid transfection (HPV+)

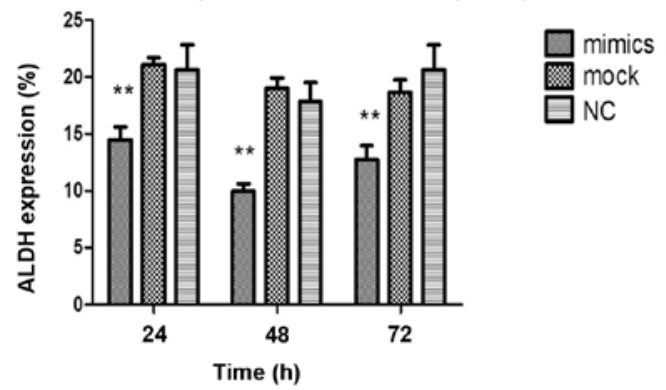

F UM-SCC47 spheroid transfection (HPV*)

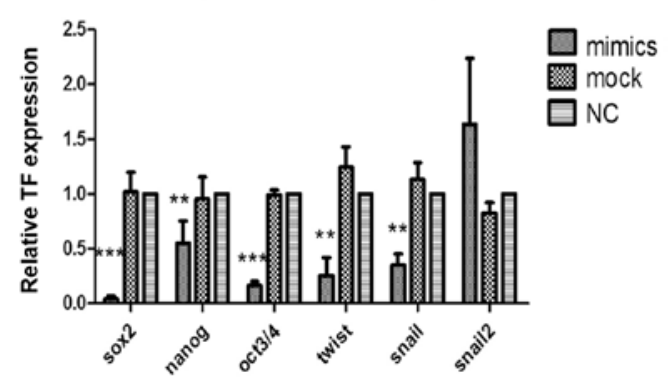

Figure 5. Overexpression of miR-34a reduces stemness- and EMT properties in HNSCC-SDC. (A and B) Change of miR-34a levels in SDC after transfection with miR-34a mimics over time (24, 48 and $72 \mathrm{~h}$ ). (C and D) Change in the ALDH expression and (E and F) expression of CSC- and EMT-related TFs in SDC $48 \mathrm{~h}$ after transfection. Mean value $\pm \mathrm{SD}$ of three independent determinations. Significant differences were ${ }^{*} \mathrm{P}<0.05,{ }^{* * *} \mathrm{P}<0.01$ and ${ }^{* * * *} \mathrm{P}<0.001$. 
A
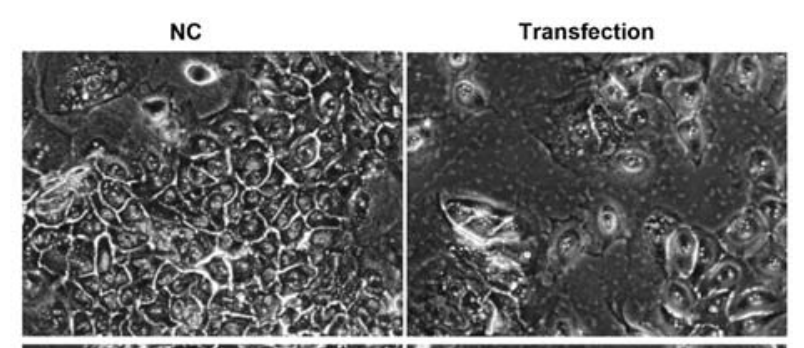

UM-ScC9

UM-ScC47

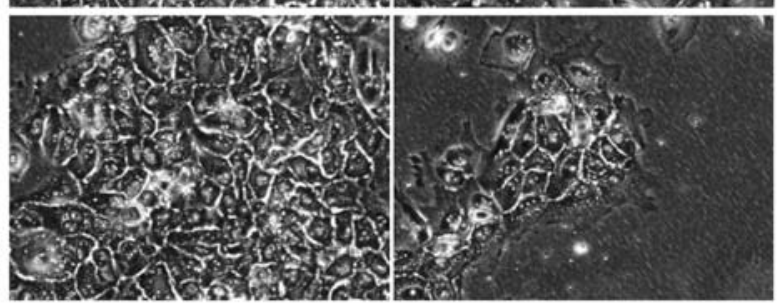

B

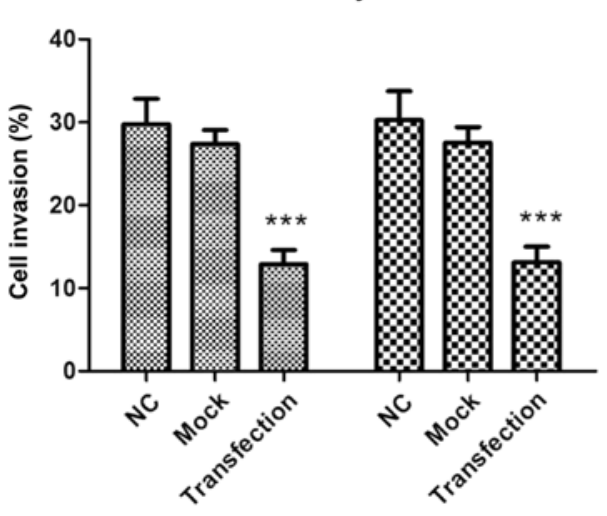

Figure 6. miR-34a transfection into HNSCC-SDC reduces invasion capacity. Cell invasion was measured by using a Matrigel coated system with the pore size of $8 \mu \mathrm{m}$. (A) Representative image of NC cells and miR-34a transfected cells after migration through the membrane. (B) NC and mock-transfected cells crossed significantly more frequently the membrane than miR-34a transfected cells. ${ }^{* * *} \mathrm{P}<0.001$. Magnification, 200 -fold.

A

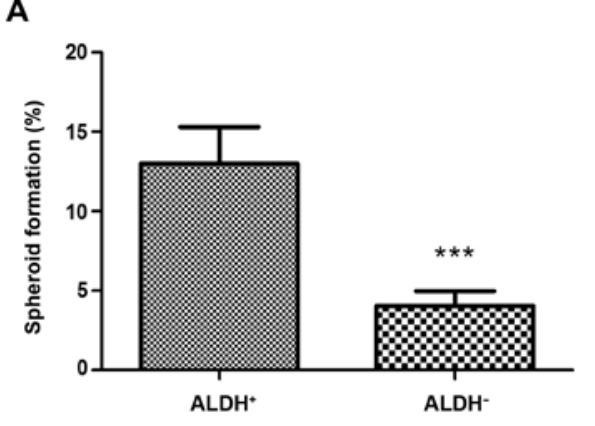

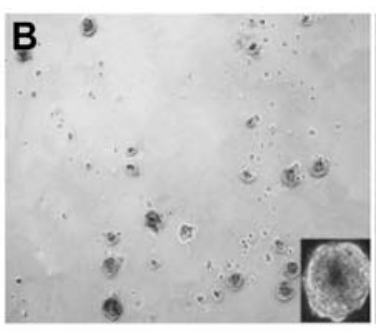
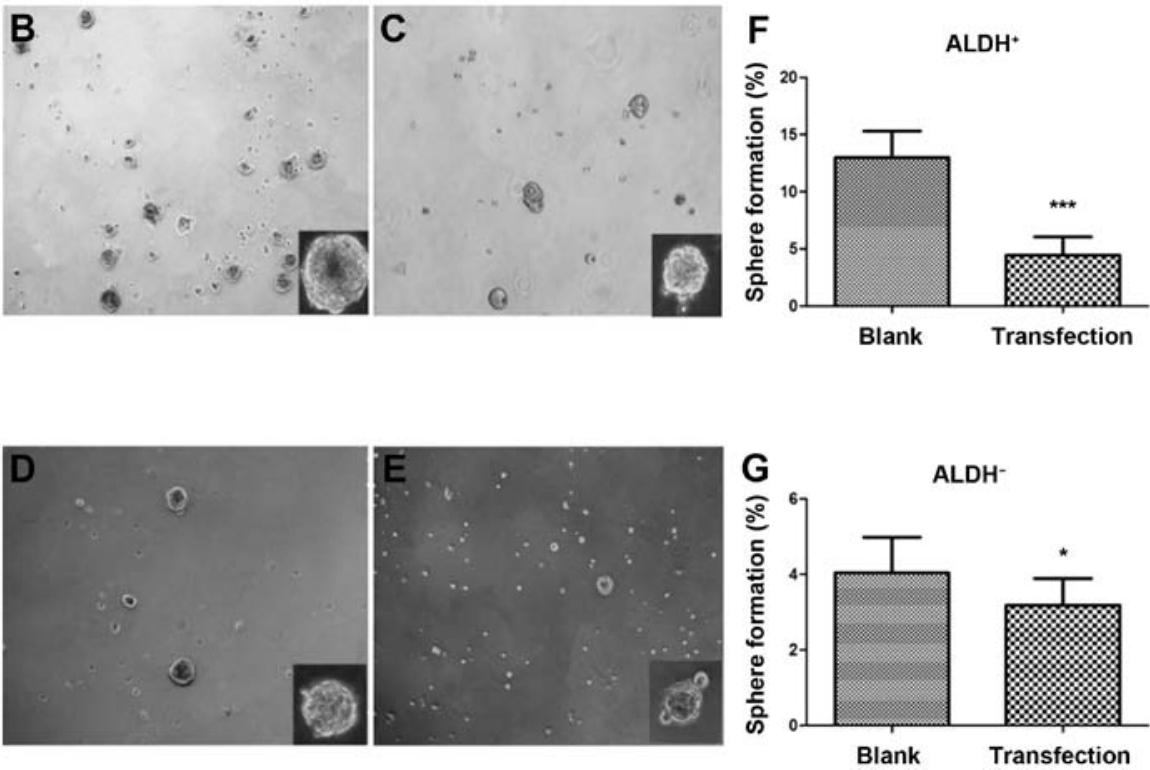

Figure 7. Representative results of anchorage-independent growth of UM-SCC9. (A) ALDH ${ }^{+}$cells formed significantly more spheroids than ALDH' cells (B) Sphere formation of $\mathrm{ALDH}^{+}$cells, (C) sphere formation in $\mathrm{ALDH}^{+}$cells after transfection of miR-34a mimics, (D) sphere formation of ALDH' cells and (E) sphere formation of ALDH' cells after transfection of miR-34a mimics. ( $F$ and G) The quantitative analysis indicated that miR-34a mimics markedly inhibited anchorage-independent cell growth in $\mathrm{ALDH}^{+}$and $\mathrm{ALDH}^{-}$cells. The mean $\pm \mathrm{SD}$ from three independent experiments is shown. ${ }^{*} \mathrm{P}<0.05,{ }^{* * *} \mathrm{P}<0.001$. Magnification of the inserted representative sphere, 200-fold.

With respect to the regulation of CSC marker, we observed downregulation of ALDH expression after miR-34a mimics transfection after 24, 48 and $72 \mathrm{~h}$ (Fig. 5C and D). The strongest change in $\mathrm{ALDH}^{+}$cell frequency was found to correlate to the highest miR-34a levels $48 \mathrm{~h}$ post-transfection (UM-SCC9 1.47-fold, UM-SCC47 1.93-fold, P<0.01). Furthermore, transfection of miR-34a mimics resulted in a decrease in CSC- and EMT-related TF mRNA expression which was tested $48 \mathrm{~h}$ post-transfection (Fig. 5E and F). Nanog, Oct3/4 and Snaill were significantly decreased over controls in the two transfected HNSCC cell lines and Sox 2 and Twist showed significant downregulation in UM-SCC47. While Snail 2 showed decreased expression in UM-SCC9 and an increase in expression in UM-SCC47.

Overexpression of miR-34a reduces the invasive capacity. For evaluation of the invasive capacity of tumor cells we used the Matrigel invasion assay. After $24 \mathrm{~h}$ of culture, the number of miR-34a mimic-transfected HNSCC-SDC that migrated through the Matrigel coated chamber was significantly decreased $(\mathrm{P}<0.001)$ compared with $\mathrm{NC}$ and mock-transfected cells (Fig. 6). The miR-34a levels after transfection were significantly increased as described above (UM-SCC9: $29.75 \pm 1.08$ vs. $12.87 \pm 0.61 \%$, UM-SCC 47 : $30.25 \pm 1.23$ vs. $13.12 \pm 0.66 \%$ ). 

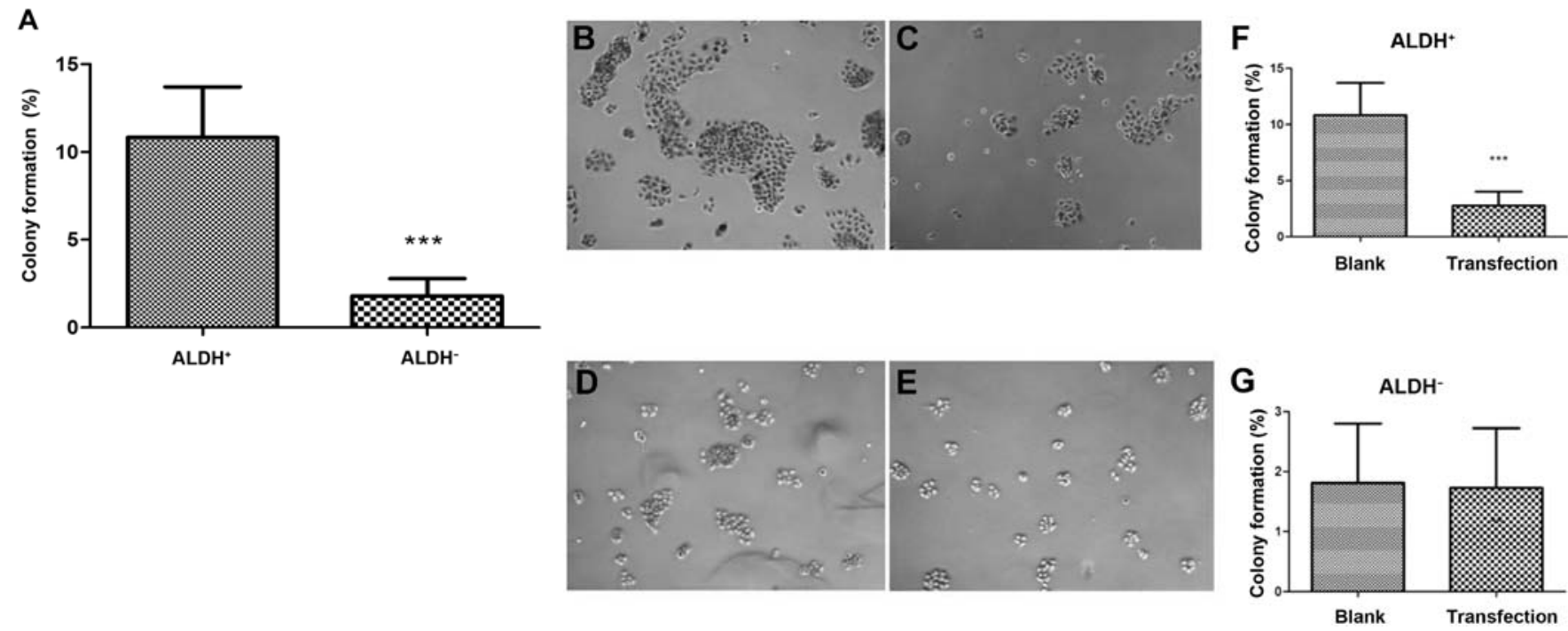

Figure 8. Representative results of colony formation in UM-SCC9. (A) $\mathrm{ALDH}^{+}$cells formed significantly more colonies than $\mathrm{ALDH}^{-}$cells. (B) Colony formation of $\mathrm{ALDH}^{+}$cells, (C) colony formation of $\mathrm{ALDH}^{+}$cells after transfection of miR-34a mimics. (D) ALDH cell colony formation and (E) colony formation of $\mathrm{ALDH}^{-}$cells after transfection of miR-34a mimics. The number of colonies and their size was significantly reduced in miR-34a mimictransfected samples compared with control-transfected cells. ( $F$ and $G$ ) Columns indicate that miR-34a mimics significantly inhibited colony formation in $\mathrm{ALDH}^{+}$cells. The mean $\pm \mathrm{SD}$ from three independent experiments is shown. ${ }^{* * *} \mathrm{P}<0.001$.

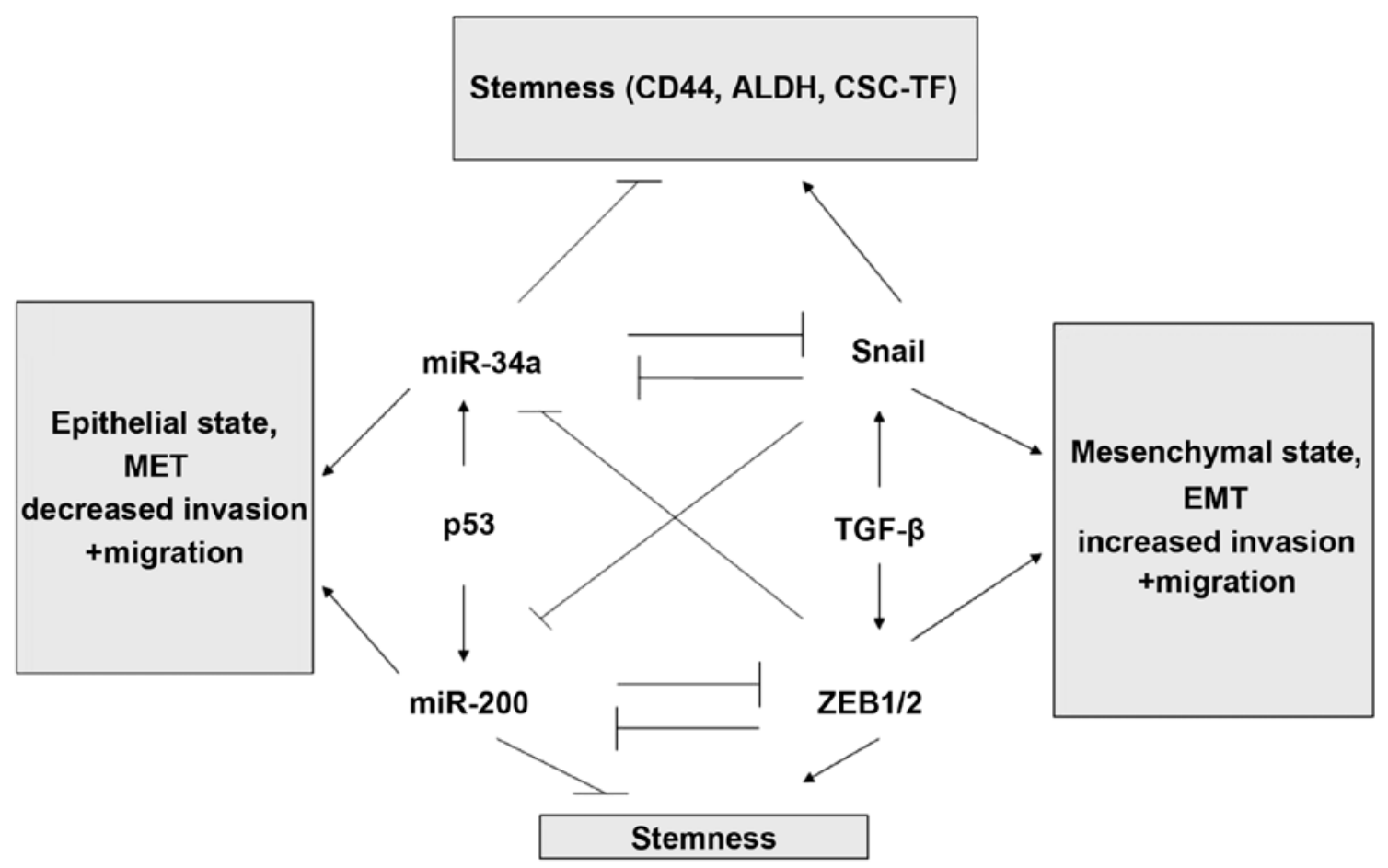

Figure 9. Summary of the regulatory roles of miR-34a in cancer. Putative interactions of miR-34a regulation by p53 and miR-200 found in this study were combined with findings from previous studies as described in the text.

Transfection of miR-34a significantly decreased the migration/invasion of UM-SCC9 and UM-SCC47 SDC by 50\%.

Decreased ability of spheroid and colony formation as well as anchorage-independent growth after miR-34a transfection. Following flow cytometric sorting of UM-SCC9 for ALDH-positivity, the role of miR-34a in spheroid and colony formation and anchorage-independent growth was assessed.
Before transfection of miR-34a, the sorted $\mathrm{ALDH}^{+}$cells showed a higher spheroid formation (Fig. 7A) and colony formation ability (Fig. 8A) than $\mathrm{ALDH}^{-}$cells. Transfection with miR-34a mimics reduced significantly the ability for anchorage-independent growth of UM-SCC9 cells. Analysis of spheroid formation showed that cells transfected with miR-34a mimics displayed much fewer and smaller spheroids than the control-transfected cells (Fig. 7B-G). The number of spheroids 
and their size were significantly decreased in miR-34a mimictransfected samples as compared with NC.

\section{Discussion}

Spheroid culture and enrichment of HNSCC-CSCs. Spheroids are spherical three-dimensional tumor cell clusters that are grown from one or several cell clones. As compared to cells cultured in monolayer, cell doubling time and the rate and pattern of spheroid growth in vitro better matches that observed in tumors in vivo (44). Spheroid cell growth has also been identified to be a property of normal tissue cells which display stem cell properties (45). Spheroid enriched CSCs can be derived from a panel of different solid malignancies such as HNSCC (10), melanoma (46), breast cancer (47) and gliosarcoma (14). Cells from these entities could be propagated by anchorage-independent growth and displayed the phenotype of non-adherent spheroids. The spheroid-forming ability was found to correspond to the expression of established CSC markers (48).

The ability of a single cell to regenerate a malignant tumor consisting of cells with heterogeneous phenotypes is one characteristic of CSCs that may help to explain some of the differences which discriminate tumor cells from differentiated somatic cells such as immortality, quiescence, invasion, metastasis and relapse after treatment. Initial studies identified CD44 ${ }^{+}$HNSCC cells that could generate new tumors in vivo $(<5,000$ cells injected into mice) (8) and concluded that CD44 is a CSC marker. ALDH has been demonstrated to be another useful CSC marker to identify CSCs in many epithelial cancers including HNSCC $(10,33,41,49-51)$. In HNSCC, Chen et al showed in immunocompromised mice that 500 injected $\mathrm{ALDH}^{+} \mathrm{HNSCC}$ cells resulted in visible tumors in all animals after 6 weeks, while $10^{4} \mathrm{ALDH}^{-}$cells failed to produce tumors (51). According to our own results and in line with the above mentioned observations, $\mathrm{ALDH}^{+}$cells showed increased CSCs properties compared to ALDH ${ }^{-}$cells derived from HNSCC cell lines (10). We and others have demonstrated a varying overlap of ALDH and CD44 populations in $\operatorname{HNSCC}(10,40)$.

In our experiments, we cultured spheroids from eight HNSCC cell lines. The eight cell lines showed varying ability to form spheroids. Sox 2, Nanog and Oct3/4 were chosen as the stemness related TFs in this project, because they were expressed at high levels, both in normal stem cells and CSC as predicted by Chickarmane and Peterson (52) and demonstrated for HNSCC by us (10). We validated the content of SDC positive for the HNSCC-CSC marker ALDH by flow cytometry and CSC-related TFs by RT-qPCR. We found that in SDC compared with corresponding MDC, the CSC-related transcription factors Sox 2 , Oct3/4 and Nanog were significantly upregulated, as was the proportion of $\mathrm{ALDH}^{+}$cells.

These findings reveal that the spheroid culture assay is a useful and efficient method to enrich cells with CSC characteristics from HNSCC cell lines and that sorting for $\mathrm{ALDH}^{+}$cells even allows for further enrichment of cells with spheroid- and clone-forming abilities. However, there was also a limitation in the spheroid culture assay to enrich for CSCs. The most important limitation was that the spheres still represent a heterogeneous population, with only a part of the cells having the ability of self-renewal (53).
MiR-34aregulates the stemness and EMTproperties in HNSCC CSCs. MiR-34a has been considered a tumor suppressor which represses stemness-related features and -functions in prostate cancer (54), breast cancer (55) and pancreatic cancer (37). An important finding of this study was that the data support the observation that miR-34a acts as tumor stemness repressor in HNSCC. Recent reports indicate downregulation of miR-34a in HNSCC cell lines and tumor samples that may promote tumor growth and tumor angiogenesis (38). Our own data confirm the observation of dysregulated miR-34a expression in HNSCC cell lines. We demonstrated that the expression in stem cellenriched HNSCC-SDC was significantly lower than in parental HNSCC-MDC. Furthermore, the frequency of $\mathrm{ALDH}^{+} \mathrm{CSC}$ was increased in SDC compared to MDC. However, transfection of miR-34a mimics into the HNSCC-SDC replenishing miR-34a levels simultaneously decreased the expression of ALDH along with the stemness-related TFs Sox 2, Nanog and Oct3/4. After upregulation of miR-34a, we found the colony and sphere formation ability and invasive capacity decreased in $\mathrm{ALDH}^{+}$cells compared to controls.

Although the direct effects of miR-34a have been studied in a wide range of different cancers, relatively few studies have investigated other possible cellular functions of miR-34a. Kim et al reported that the p53/miR-34a axis regulates Snail1dependent EMT. Among the proto-type EMT regulators (ZEB1/2, Snail1, Slug), also miR-34a directly targets Snail1 (56). According to a study by Siemens et al (57) miR-34a and Snail forms a double-negative feedback loop to regulate EMT. Activated p53 downregulates the EMT-inducing transcription factor Snaill by upregulation of miR-34a. On the other hand the TF Snaill binds to the E boxes in miR-34a promoters to repress its expression. However, indirect downregulation of ZEB1/2 and Slug, which are miR-200 targets, may occur via de-repression of the Snail-regulated miR-200 promoters after miR-34a activation (57).

In this study, we compared EMT-properties of SDC to MDC after transfection with miR-34a mimics to further characterize the role of this molecule in EMT. We were able to demonstrate that the transfection of miR-34a mimics led to downregulation of EMT-related TFs in SDC. In line with these findings, the invasive capacity of these cells was reduced, indicating an implication of miR-34a in the regulation of EMT in HNSCC. This observation may be of future clinical relevance since, in a prostate cancer mouse model systemic delivery of miR-34a inhibited formation of metastasis (54). Therefore, the mechanisms of miR-34a action and regulation presented here may have diagnostic and therapeutic relevance in the future.

In our experiments, the EMT-related TF Snaill and CSC-related TFs showed decreased expression in HNSCC cell lines after transfection of miR-34a mimics, indicating that the miR-34a may play multiple roles in suppressing mesenchymal traits and inhibiting stemness properties. A similar phenomenon was also reported in pancreatic cancer, where a restoration of miR-34a reduced CSC properties and inhibited the EMT (58). In breast cancer cells, it was demonstrated that re-expression of miR-200 suppressed EMT-related genes and stemness properties (59). C-MYC and CD44 represent direct miR-34a targets $(54,60-62)$, whereas, the effect on the other stemness markers/factors is presumably indirect (Fig. 9). 
Taken together, we were able to demonstrate that miR-34a is involved in the regulation of EMT and invasive properties of CSC by quantifying TFs involved in the regulation of EMT (Snail and Twist) and by conducting functional assays displaying colony forming and invasive capacities. Previously, we demonstrated as a property of HNSCC-CSC an increased invasive capacity and expression of EMT-markers such as $\alpha$-smooth muscle actin and vimentin, while at the same time the expression of the adhesion molecule E-cadherin was significantly reduced (10). Our experiments demonstrated that this can be reversed by transfer of miR34a-mimics in HNSCC in vitro. Evidence for an accumulation of the formulated miR34a mimics was reported in the spleen, lung and kidney (63), suggesting a potential opportunity for cancer therapeutic development.

Influence of the HPV on HNSCC-CSC characteristics. $\mathrm{HPV}^{+}$- and $\mathrm{HPV}^{-} \mathrm{HNSCC}$ show distinct characteristics in their biological and clinical behavior. We found in primary oropharyngeal squamous cell carcinoma, that HPV-DNA ${ }^{+}$tumors had a lower ALDH1A1 expression and the HPV-DNA ${ }^{-}$group had higher expression as measured by immunohistochemistry (41). ALDH1A1 is not only a CSC marker but it also serves as a prognostic biomarker in $\operatorname{HNSCC}(33,64)$. Moreover, we have assessed the utility of ALDH1A1 staining-intensity as measure for its expression as a prognostic biomarker in surgically treated HNSCC patients. We were able to demonstrate a significant correlation between ALDH1A1 staining intensity and prognosis (33). HNSCC patients with strong ALDH1A1 expression, had a significantly inferior 5-year overall survival compared with those HNSCC patients who had weak ALDH1A1 expression (65). On the basis of these observations, we hypothesized that the improved clinical outcome of patients with $\mathrm{HPV}^{+} \mathrm{HNSCC}$ may be due to the fact that $\mathrm{HPV}^{+} \mathrm{HNSCC}$ has a lower expression level of ALDH than $\mathrm{HPV}^{-} \mathrm{HNSCC}$ and a lower CSC content. Our data support these clinical results, as also in cell culture $\mathrm{HPV}^{+} \mathrm{HNSCC}$ cell lines have a lower expression level of ALDH compared to the HPV $\mathrm{HP}^{-}$group. However, the number of tested cell lines was limited and may represent characteristics specific to HNSCC-lines that have the ability to grow in vitro.

In conclusion, in this study, we found that increased miR-34a can suppress CSC-like properties of HNSCC and EMT. This was demonstrated by the downregulation of CSCand EMT-related TFs, colony- and spheroid-forming abilities and decreased invasive capacity. These findings suggest that miR-34a may play important roles in these processes and may therefore have a potential in novel therapeutic regimen or in combination with existing treatments of HNSCC: a) by reducing the frequency of the CSC-phenotype which is held responsible for therapy-resistance and b) by reducing the formation of novel metastases by inhibiting EMT. However, routes to apply this molecule in a therapeutic setting in humans remain to be explored.

\section{References}

1. Kamangar F, Dores GM and Anderson WF: Patterns of cancer incidence, mortality, and prevalence across five continents: Defining priorities to reduce cancer disparities in different geographic regions of the world. J Clin Oncol 24: 2137-2150, 2006.
2. Jemal A, Siegel R, Ward E, Hao Y, Xu J, Murray T and Thun MJ: Cancer statistics, 2008. CA Cancer J Clin 58: 71-96, 2008.

3. Pignon JP, Baujat B and Bourhis J: Individual patient data metaanalyses in head and neck carcinoma: what have we learnt? Cancer Radiother 9: 31-36, 2005 (In French).

4. Reya T, Morrison SJ, Clarke MF and Weissman IL: Stem cells, cancer, and cancer stem cells. Nature 414: 105-111, 2001.

5. Chan KS, Espinosa I, Chao M, Wong D, Ailles L, Diehn M, Gill H, Presti J Jr, Chang HY, van de Rijn M, et al: Identification, molecular characterization, clinical prognosis, and therapeutic targeting of human bladder tumor-initiating cells. Proc Natl Acad Sci USA 106: 14016-14021, 2009.

6. Al-Hajj M, Wicha MS, Benito-Hernandez A, Morrison SJ and Clarke MF: Prospective identification of tumorigenic breast cancer cells. Proc Natl Acad Sci USA 100: 3983-3988, 2003.

7. Dalerba P, Dylla SJ, Park IK, Liu R, Wang X, Cho RW, Hoey T, Gurney A, Huang EH, Simeone DM, et al: Phenotypic characterization of human colorectal cancer stem cells. Proc Natl Acad Sci USA 104: 10158-10163, 2007.

8. Prince ME, Sivanandan R, Kaczorowski A, Wolf GT, Kaplan MJ, Dalerba P, Weissman IL, Clarke MF and Ailles LE: Identification of a subpopulation of cells with cancer stem cell properties in head and neck squamous cell carcinoma. Proc Natl Acad Sci USA 104: 973-978, 2007.

9. Hermann PC, Huber SL, Herrler T, Aicher A, Ellwart JW, Guba M, Bruns CJ and Heeschen C: Distinct populations of cancer stem cells determine tumor growth and metastatic activity in human pancreatic cancer. Cell Stem Cell 1: 313-323, 2007.

10. Liu X, Wang C, Chen Z, Jin Y, Wang Y, Kolokythas A, Dai Y and Zhou X: MicroRNA-138 suppresses epithelial-mesenchymal transition in squamous cell carcinoma cell lines. Biochem J 440: 23-31, 2011.

11. Nguyen LV, Vanner R, Dirks P and Eaves CJ: Cancer stem cells: An evolving concept. Nat Rev Cancer 12: 133-143, 2012.

12. Lee HE, Kim JH, Kim YJ, Choi SY, Kim SW, Kang E, Chung IY, Kim IA, Kim EJ, Choi Y, et al: An increase in cancer stem cell population after primary systemic therapy is a poor prognostic factor in breast cancer. Br J Cancer 104: 1730-1738, 2011.

13. Jiang W, Peng J, Zhang Y, Cho WC and Jin K: The implications of cancer stem cells for cancer therapy. Int J Mol Sci 13: 16636-16657, 2012.

14. Ghods AJ, Irvin D, Liu G, Yuan X, Abdulkadir IR, Tunici P, Konda B, Wachsmann-Hogiu S, Black KL and Yu JS: Spheres isolated from 9L gliosarcoma rat cell line possess chemoresistant and aggressive cancer stem-like cells. Stem Cells 25: 1645-1653, 2007.

15. Azari H, Rahman M, Sharififar S and Reynolds BA: Isolation and expansion of the adult mouse neural stem cells using the neurosphere assay. J Vis Exp 45: 2393, 2010.

16. Todaro M, Alea MP, Di Stefano AB, Cammareri P, Vermeulen L, Iovino F, Tripodo C, Russo A, Gulotta G, Medema JP, et al: Colon cancer stem cells dictate tumor growth and resist cell death by production of interleukin-4. Cell Stem Cell 1: 389-402, 2007.

17. Schatton T,Murphy GF, Frank NY, Yamaura K, Waaga-Gasser AM, Gasser M, Zhan Q, Jordan S, Duncan LM, Weishaupt C, et al: Identification of cells initiating human melanomas. Nature 451: 345-349, 2008.

18. Okamoto A, Chikamatsu K, Sakakura K, Hatsushika K, Takahashi G and Masuyama K: Expansion and characterization of cancer stem-like cells in squamous cell carcinoma of the head and neck. Oral Oncol 45: 633-639, 2009.

19. Chiou SH, Yu CC, Huang CY, Lin SC, Liu CJ, Tsai TH, Chou SH, Chien CS, Ku HH and Lo JF: Positive correlations of Oct-4 and Nanog in oral cancer stem-like cells and high-grade oral squamous cell carcinoma. Clin Cancer Res 14: 4085-4095, 2008.

20. Wu KJ and Yang MH: Epithelial-mesenchymal transition and cancer stemness: The Twist1-Bmil connection. Biosci Rep 31: 449-455, 2011.

21. Santisteban M, Reiman JM, Asiedu MK, Behrens MD, Nassar A, Kalli KR, Haluska P, Ingle JN, Hartmann LC, Manjili MH, et al: Immune-induced epithelial to mesenchymal transition in vivo generates breast cancer stem cells. Cancer Res 69: 2887-2895, 2009.

22. Mani SA, Guo W, Liao MJ, Eaton EN, Ayyanan A, Zhou AY, Brooks M, Reinhard F, Zhang CC, Shipitsin M, et al: The epithelial-mesenchymal transition generates cells with properties of stem cells. Cell 133: 704-715, 2008.

23. Chen C, Zimmermann M, Tinhofer I, Kaufmann AM and Albers AE: Epithelial-to-mesenchymal transition and cancer stem(-like) cells in head and neck squamous cell carcinoma. Cancer Lett 338: 47-56, 2013. 
24. Hindriksen S and Bijlsma MF: Cancer stem cells, EMT, and developmental pathway activation in pancreatic tumors. Cancers (Basel) 4: 989-1035, 2012.

25. Micalizzi DS, Farabaugh SM and Ford HL: Epithelialmesenchymal transition in cancer: Parallels between norma development and tumor progression. J Mammary Gland Biol Neoplasia 15: 117-134, 2010.

26. Reddy BY, Lim PK, Silverio K, Patel SA, Won BW and Rameshwar P: The microenvironmental effect in the progression, metastasis, and dormancy of breast cancer: A model system within bone marrow. Int J Breast Cancer 2012: 721659, 2012.

27. Phinney DG: Twist, epithelial-to-mesenchymal transition, and stem cells. Stem Cells 29: 3-4, 2011

28. van der Pluijm G: Epithelial plasticity, cancer stem cells and bone metastasis formation. Bone 48: 37-43, 2011.

29. Korpal M,Lee ES, Hu G and Kang Y: The miR-200 family inhibits epithelial-mesenchymal transition and cancer cell migration by direct targeting of E-cadherin transcriptional repressors ZEB1 and ZEB2. J Biol Chem 283: 14910-14914, 2008.

30. Viñas-Castells R, Beltran M, Valls G, Gómez I, García JM, Montserrat-Sentís B, Baulida J, Bonilla F, de Herreros AG and Díaz VM: The hypoxia-controlled FBXL14 ubiquitin ligase targets SNAIL1 for proteasome degradation. J Biol Chem 285 : 3794-3805, 2010.

31. Martin A and Cano A: Tumorigenesis: Twist1 links EMT to selfrenewal. Nat Cell Biol 12: 924-925, 2010.

32. Yang MH, Hsu DS, Wang HW, Wang HJ, Lan HY, Yang WH, Huang CH, Kao SY, Tzeng CH, Tai SK, et al: Bmil is essential in Twist1-induced epithelial-mesenchymal transition. Nat Cell Biol 12: 982-992, 2010

33. Qian X, Wagner S, Ma C, Coordes A, Gekeler J, Klussmann JP, Hummel M, Kaufmann AM and Albers AE: Prognostic significance of ALDH1A1-positive cancer stem cells in patients with locally advanced, metastasized head and neck squamous cell carcinoma. J Cancer Res Clin Oncol 140: 1151-1158, 2014.

34. Hugo H, Ackland ML, Blick T, Lawrence MG, Clements JA Williams ED and Thompson EW: Epithelial-mesenchymal and mesenchymal-epithelial transitions in carcinoma progression. J Cell Physiol 213: 374-383, 2007.

35. Bartel DP: MicroRNAs: Genomics, biogenesis, mechanism, and function. Cell 116: 281-297, 2004.

36. Calin GA and Croce CM: MicroRNA signatures in human cancers. Nat Rev Cancer 6: 857-866, 2006.

37. Ji Q, Hao X, Zhang M, Tang W, Yang M, Li L, Xiang D, Desano JT, Bommer GT, Fan D, et al: MicroRNA miR-34 inhibits human pancreatic cancer tumor-initiating cells. PLoS One 4: e6816, 2009.

38. Kumar B, Yadav A, Lang J, Teknos TN and Kumar P. Dysregulation of microRNA-34a expression in head and neck squamous cell carcinoma promotes tumor growth and tumor angiogenesis. PLoS One 7: e37601, 2012.

39. Pfaffl MW: A new mathematical model for relative quantification in real-time RT-PCR. Nucleic Acids Res 29: e45, 2001.

40. Clay MR, Tabor M, Owen JH, Carey TE, Bradford CR, Wolf GT, Wicha MS and Prince ME: Single-marker identification of head and neck squamous cell carcinoma cancer stem cells with aldehyde dehydrogenase. Head Neck 32: 1195-1201, 2010.

41. Qian X, Wagner S, Ma C, Klussmann JP, Hummel M, Kaufmann AM and Albers AE: ALDH1-positive cancer stem-like cells are enriched in nodal metastases of oropharyngeal squamous cell carcinoma independent of HPV status. Oncol Rep 29: 1777-1784, 2013.

42. Klinghammer K, Raguse JD, Plath T, Albers AE, Joehrens K, Zakarneh A, Brzezicha B, Wulf-Goldenberg A, Keilholz U, Hoffmann J, et al: A comprehensively characterized large panel of head and neck cancer patient-derived xenografts identifies the mTOR inhibitor everolimus as potential new treatment option. Int J Cancer 136: 2940-2948, 2014.

43. Ling GQ, Chen DB, Wang BQ and Zhang LS: Expression of the pluripotency markers Oct3/4, Nanog and Sox 2 in human breas cancer cell lines. Oncol Lett 4: 1264-1268, 2012.

44. Santini MT, Rainaldi G and Indovina PL: Multicellular tumour spheroids in radiation biology. Int J Radiat Biol 75: 787-799, 1999.

45. Wicha MS, Liu S and Dontu G: Cancer stem cells: an old idea - a paradigm shift. Cancer Res 66: 1883-1890; discussion 1895-1886, 2006.

46. Fang D, Nguyen TK, Leishear K, Finko R, Kulp AN, Hotz S, Van Belle PA, Xu X, Elder DE and Herlyn M: A tumorigenic subpopulation with stem cell properties in melanomas. Cancer Res 65: 9328-9337, 2005.
47. Ponti D, Costa A, Zaffaroni N, Pratesi G, Petrangolini G, Coradini D, Pilotti S, Pierotti MA and Daidone MG: Isolation and in vitro propagation of tumorigenic breast cancer cells with stem/progenitor cell properties. Cancer Res 65: 5506-5511, 2005.

48. Kuch V, Schreiber C, Thiele W, Umansky V and Sleeman JP Tumor-initiating properties of breast cancer and melanoma cells in vivo are not invariably reflected by spheroid formation in vitro, but can be increased by long-term culturing as adherent monolayers. Int J Cancer 132: E94-E105, 2013.

49. Ginestier C, Hur MH, Charafe-Jauffret E, Monville F, Dutcher J, Brown M, Jacquemier J, Viens P, Kleer CG, Liu S, et al: ALDH1 is a marker of normal and malignant human mammary stem cells and a predictor of poor clinical outcome. Cell Stem Cell 1: 555-567, 2007.

50. Ma S, Chan KW, Lee TK, Tang KH, Wo JY, Zheng BJ and Guan XY: Aldehyde dehydrogenase discriminates the CD133 liver cancer stem cell populations. Mol Cancer Res 6: 1146-1153, 2008.

51. Chen YC, Chen YW, Hsu HS, Tseng LM, Huang PI, Lu KH, Chen DT, Tai LK, Yung MC, Chang SC, et al: Aldehyde dehydrogenase 1 is a putative marker for cancer stem cells in head and neck squamous cancer. Biochem Biophys Res Commun 385: 307-313, 2009.

52. Chickarmane V and Peterson C: A computational model for understanding stem cell, trophectoderm and endoderm lineage determination. PLoS One 3: e3478, 2008.

53. Jensen JB and Parmar M: Strengths and limitations of the neurosphere culture system. Mol Neurobiol 34: 153-161, 2006.

54. Liu C, Kelnar K, Liu B, Chen X, Calhoun-Davis T, Li H, Patrawala L, Yan H, Jeter C, Honorio S, et al: The microRNA miR-34a inhibits prostate cancer stem cells and metastasis by directly repressing CD44. Nat Med 17: 211-215, 2011.

55. Park EY, Chang E, Lee EJ, Lee HW, Kang HG, Chun KH, Woo YM, Kong HK, Ko JY, Suzuki H, et al: Targeting of miR34a-NOTCH1 axis reduced breast cancer stemness and chemoresistance. Cancer Res 74: 7573-7582, 2014.

56. Kim NH, Kim HS, Li XY, Lee I, Choi HS, Kang SE, Cha SY, Ryu JK, Yoon D, Fearon ER, et al: A p53/miRNA-34 axis regulates Snaill-dependent cancer cell epithelial-mesenchymal transition. J Cell Biol 195: 417-433, 2011.

57. Siemens H, Jackstadt R, Hünten S, Kaller M, Menssen A, Götz U and Hermeking H: miR-34 and SNAIL form a double-negative feedback loop to regulate epithelial-mesenchymal transitions. Cell Cycle 10: 4256-4271, 2011.

58. Nalls D, Tang SN, Rodova M, Srivastava RK and Shankar S: Targeting epigenetic regulation of miR-34a for treatment of pancreatic cancer by inhibition of pancreatic cancer stem cells. PLoS One 6: e24099, 2011.

59. Chang CJ, Chao CH, Xia W, Yang JY, Xiong Y, Li CW, Yu WH, Rehman SK, Hsu JL, Lee HH, et al: p53 regulates epithelialmesenchymal transition and stem cell properties through modulating miRNAs. Nat Cell Biol 13: 317-323, 2011.

60. Cannell IG and Bushell M: Regulation of Myc by miR-34c: A mechanism to prevent genomic instability? Cell Cycle 9: 2726-2730, 2010

61. Christoffersen NR, Shalgi R, Frankel LB, Leucci E, Lees M, Klausen M, Pilpel Y, Nielsen FC, Oren $M$ and Lund AH: p53-independent upregulation of miR-34a during oncogeneinduced senescence represses MYC. Cell Death Differ 17: 236-245, 2010

62. Kong YW, Cannell IG, de Moor CH, Hill K, Garside PG, Hamilton TL, Meijer HA, Dobbyn HC, Stoneley M, Spriggs KA, et al: The mechanism of micro-RNA-mediated translation repression is determined by the promoter of the target gene. Proc Natl Acad Sci USA 105: 8866-8871, 2008.

63. Bader AG, Brown D and Winkler M: The promise of microRNA replacement therapy. Cancer Res 70: 7027-7030, 2010.

64. Koukourakis MI, Giatromanolaki A, Tsakmaki V, Danielidis V and Sivridis E: Cancer stem cell phenotype relates to radiochemotherapy outcome in locally advanced squamous cell head-neck cancer. Br J Cancer 106: 846-853, 2012.

65. Xu J, Müller S, Nannapaneni S, Pan L, Wang Y, Peng X, Wang D, Tighiouart M, Chen Z, Saba NF, et al: Comparison of quantum dot technology with conventional immunohistochemistry in examining aldehyde dehydrogenase $1 \mathrm{~A} 1$ as a potential biomarker for lymph node metastasis of head and neck cancer. Eur J Cancer 48: 1682-1691, 2012. 